\title{
Social capital and firm performance: A study on manufacturing and services firms in Vietnam
}

\author{
Hanh Tien Thi Nguyen ${ }^{\mathrm{a}}$ and Tri Minh Ha $\mathrm{a}^{\text {* }}$
}

aInternational University, Vietnam National University - HCMC, Vietnam

\begin{tabular}{l}
\hline C H R O N I C L E \\
\hline Article history: \\
Received: February 19, 2020 \\
Received in revised format: \\
March 272020 \\
Accepted: March 29, 2020 \\
Available online: \\
March 30, 2020 \\
\hline Keywords: \\
Social capital \\
Knowledge transfer \\
Innovation \\
Firm performance \\
Structural equation modeling \\
Vietnam
\end{tabular}

\section{A B S T R A C T}

This article investigates the causal connection between social capital (SC), knowledge transfer,
innovation and firm performance. Based on existing literature on social capital, we develop a
research model showing that three dimensions of social capital, including network ties, trust and
shared visions, have positive relationships with company performance via two mediators, namely
knowledge transfer and innovation. Using a sample of 153 Vietnamese firms, including one to two
respondents from each firm, our study applied structural equation modeling to confirm the
hypotheses. The results show that all three dimensions of social capital were positively related to
firm performance with knowledge transfer and innovation acting as mediators. Knowledge transfer
and the company's innovation were found to have a strong association with each other.
Academically, this paper offers an opportunity to investigate social capital in terms of other factors
in one specific industry. Practically, our findings motivate firms to focus on improving knowledge
transfer on both quantity and quality prospects to boost firm performance.

(C) 2020 by the authors; licensee Growing Science, Canada

\section{Introduction}

Social capital (SC) encompasses "the sum of the actual and potential resources embedded within, available through, and derived from the network of relationships possessed by an individual or social unit" (Nahapiet \& Ghoshal, 1998, p. 243). SC is increasingly perceived as remarkable and considered by many as an origin of precious resources (Adler \& Kwon, 2002). As an illustration, organizations can improve their performance and skills by focusing on and synthesizing the SC assets of their employees (Van Wijk, Jansen \& Lyles, 2008). Considering the mechanism of how social networks and capital work in East Asian cultures, researchers such as Dalton, Pham and Ong (2002) disclosed how crucial the family roles are within networks, and how family ties stay as key network nodes for many people. Additionally, the method of social modernization not only undermines traditional family-based networks but also expands them to include other networks in the areas of labor and social groups. For instance, those who are well-informed or youthful are more probable to be subjected to a variety of dense social networks obtained and expanded from household networks (Dalton et al., 2002). Obtaining and extracting social assets from social networks is becoming essential for private companies in the era of continually developing and emerging economies, especially for small and medium-sized enterprises (SMEs) (Le Van, Nguyen, Nguyen \& Simioni, 2018). In the framework of a developing economy such as Vietnam, it is becoming increasingly important for companies to depend on their SC, as Asian markets are intensive networking (Hitt, Lee \& Yucel, 2002). In addition, the use of SC is also of particular importance to SMEs because of the skewed and corrupt design of their target markets (Le Van et al., 2018). This research, therefore, made an effort to play a part in the knowledge base by evaluating how SC had an impact on company performance through network links, trust, and mutual vision, and facilitated by knowledge transfer and innovation. This research sample is composed of companies in the manufacturing, service and trading industries.

* Corresponding author. Tel.: +84903189699

E-mail address: hmtri@hcmiu.edu.vn (T. M. Ha) 


\section{Materials and methods}

\subsection{Materials}

The foundations of "SC" lies within its derivatives, social relations and social resources, which are proposed to be beneficial for individuals and collective groups (Ali-Hassan, 2009). These social resources, especially those that enhance firms' competencies, are argued to be vital in a fast-paced, competitive, and highly unstable knowledge-based economy (Subramaniam \& Youndt, 2005). As shown by scholars, SC provides firms with a gateway to inaccessible resources such as novel, refined information (Uzzi, 1997) and innovative-supporting information that circulate through social network nodes (Burt, 1987). Aside from SC, the extent of a firm's competencies and successfulness is greatly determined by its innovation capabilities (Klomp \& van Leeuwen, 2001) and knowledge-sharing mechanisms (Haak-Saheem, Darwish \& Al-Nasser, 2016). To elaborate, according to Kogut and Zander (1996), the act of knowledge sharing serves as a byproduct of various firm strengths, including innovation and performances. In addition, a firm's abilities to generate novel ideas and products greatly rely on its innovation capacities, thus enhance its learning and success rates (Hurley, Thomas \& Hult, 1998). Moreover, a significant portion of SC scholars emphasizes on firm performance and information sharing as research objects (Nguyen \& $\mathrm{Ha}, 2019)$. Regarding the causal relationship between social networks and outcomes, studies often rely on learning mechanism to propose theoretical explanations (e.g. Nahapiet \& Ghoshal, 1998). In terms of clarifying the connections between SC and knowledge transfer, various studies examined a wide variety of dimensions, such as intention to share (Chow, 2008); sharing benefits (Maurer, Bartsch \& Ebers, 2011). In terms of organizational outcomes, there is evidence that illustrates the link between trust and performance, specifically improving productivity and revenues (Helliwell, 1996; Inge Jenssen \& Greve, 2002). In addition, the SC factors that are proven to be influential to small-scaled companies by generating information and other resources as well as enhancing competencies and knowledge sharing are: "network ties", "trust," and "consensus of vision among network members" (Gronum, Verreynne \& Kastelle, 2012; Wu, 2008). There exists a considerable body of studies researching about the impacts of SC measurement on company innovation (Cook, Hardin \& Levi, 2005), market innovation (i.e., penetration of market segments, exploitation of territorial areas) (Chuang, 2005), product development (Salavou \& Lioukas, 2003). Besides, many researchers found the correlation between innovation and firm performances (Dato-on, Banerjee \& Roy, 2017; Gronum et al., 2012) which are affected by dimensions of SC. Thus, Love, Roper and Du (2009) suggested that people who are open for innovation usually benefit more. However, there are no research papers attempting to combine the effect of SC on three factors, intention to knowledge sharing, innovation, and firm performances, especially in Vietnam. Current topics of research include the measurement of SC (Le, 2007; Nguyen, 2013; Tran, 2006), the mere relationship between general SC and company performance (Tran, 2003), or social, human, and physical capital in general (Le Van et al., 2018). Currently, firm performance has yet to be investigated with relevant data analysis in a local context such as Vietnam, not to mention the two factors, namely knowledge transfer and innovation as mediators. Furthermore, it is suggested by Maurer et al. (2011) that SC should be explored in the context of globalization, specifically the mediating effects (the effects of knowledge transfer or others) of SC that affects performances, such as financial performance.

\section{SC theory}

The foundation of SC theory lies in people's expectation to ensure and harvest future benefits by their investments in social resources as well as by their permission for other parties to access the SC (Lin, 1999). The evolution of SC theory provides crucial theoretical tools to shed light on the complementing relationships of SC and firm performances as well as their driving factors. Furthermore, the economic benefits and returns of SC have been continuously discussed by scholars since small firms often have limited accesses to resources because of their inadequate networks. This leads to the belief that collaborating and networking is vital, hence the foundation of SC theory. The networks can be categorized by shared norms and visions among network members (Granovetter, 1983; Putnam, 1995).

\section{Social exchange theory}

Social exchange theory argues that by participating in networking activities, people are expected to yield future returns in the form of tangible and intangible resources, thus maximizing the profits and benefits (Burns, 1973; Thibaut, 2017; Thibaut \& Kelly, 1959). A study by Nahapiet and Ghoshal (1998) contributed to the theory by revealing people's intentions to share their knowledge in networks are subjected to their expectations of gaining future rewards from communities.

\subsection{Hypotheses development}

In terms of the structural dimension of SC, network ties are an important element of SC since the ties of network generate possibilities for the transfer of SC (Adler \& Kwon, 2002). With respect to the cognitive dimension, this research only monitors the cognitive dimension with a shared vision, which is the conduct arising from the understanding of collectivity or the power of consensus. That is to say, mutual vision starts to grow when people concur with prevalent techniques or strategies for obtaining the required outcomes and when people are eager to engage in a long-term partnership (Jarillo, 1988; Coleman, 1988). Among the facets of relational dimension, namely trust, norms, and identification, this article relies on trust because 
of spatial limitations and because of its critical characteristics in influencing the development and distribution of information between companies (Dodgson, 1993). A summary of the literature in the previous section has proved that knowledge sharing occurring in the form of networks can turn the power of SC into firms' innovation projects, leading to concrete firm performance enhancement. Following the past research of the influence of SC on business, this study used the financial measures concerning success, profitability, and growth. Fig. 1 presents the study’s proposed research model.

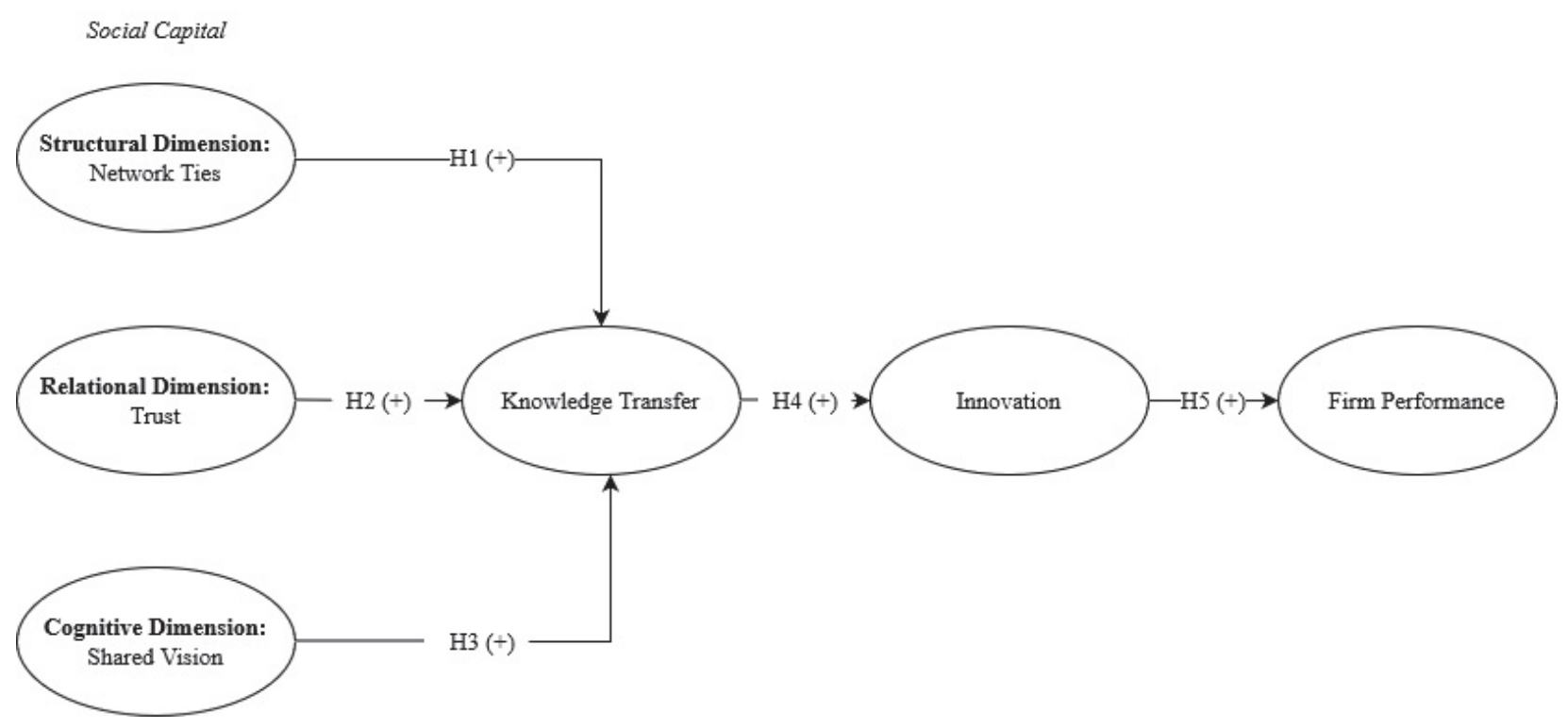

Fig. 1. The proposed model

Literature has pointed out the correlation between SC and knowledge transfer through a lot of studies (Van Mijk, Jansen \& Lyles, 2008). SC is regarded as a primary reference for the generations of the unique value-creating resources, which are intrinsic within any firm's relationships' network (McEvily \& Zaheer, 1999). It enables individuals and firms to gain from shared comprehension gathering by close-connected associates and networking partners (Hansen 1999; McEvily et al., 1999). Social embeddedness is discovered to enable companies to interchange very detailed information (Uzzi, 1997). Chow (2008) demonstrated the critical impact of SC dimensions like social ties, trust and shared objectives on organizational members' sharing intention. SC between the members within the networking was discovered to affect small-scaled companies' performance by creating values, supplying details, particulars, understanding and expanding innovative abilities (Andersson et al., 2002; Gronum et al., 2012; Wu, 2008).

H1: Network ties are positively related to knowledge transfer.

H2: Trust has a positive impact on knowledge transfer.

H3: Shared vision has a positive impact on knowledge transfer.

The literature of innovation has proved that knowledge transfer contributes a favorable influence on innovation regarding products (Miller, Besser \& Malshe, 2007) and firms' processes (Roper et al., 2008). The ability of knowledge transformation and exploitation of any firms may control the innovation levels of the firm, for instance, a new method of solving problems and new rapid reaction regarding products to the demand of market (Du Plessis, 2007). Information and technology handover from one department of a firm to other departments can prompt the evolution of new inventions since it smoothens specialized knowledge resources integration and combination process (Smith, Collins, Christopher \& Clark, 2005). As a result, knowledge transfer is able to have the contribution of reallocating existing resources or combining new ones to create innovation result (Song, Droge, Hanvanich \& Calantone, 2005).

H4: Knowledge transfer has a positive impact on innovation.

Given the present context of a constantly evolving and unpredictable environment, innovation is considered by many to be the driving force of strategic competitiveness and sustainable value (Subramaniam \& Youndt, 2005). Consequently, bringing various aspects of innovation to light in order to understand its relationship with firm performances has been done gradually by many scholars (Clifton, Keast, Pickernell \& Senior, 2010; Liao, Wang, Chuang, Shih \& Liu, 2010). Not only does innovation leverage existing resources to drive efficiency, but it is also likely to propel radical transformation that introduces new processes, mechanisms, or intangible assets (Wang \& Wang, 2012). Firms that manage to achieve higher levels of innovation 
might be able to achieve a leap in performance or significantly increase their profit margins (Sadikoglu \& Zehir, 2010). Overall, it can be considered that innovation is vital and positively impacts on organizational efficiency and quality (Parasuraman, 2010). On the basis of the mentioned arguments, it is expected that:

H5: Innovation is positively associated with firm performance.

\subsection{Method}

\subsubsection{Study participants}

The survey targeted respondents having a managing position (i.e., general manager and/or line manager) or above to validate innovative development and firm performance details. In addition, most line managers come from the Sales and marketing department, where the transfer of knowledge and networking is essential. This study consisted of 153 distinctive companies with 104 coming from Services industry and 49 coming from Manufacturing. There were 71 companies in Southern Vietnam (e.g. Unilever, Acecook), 49 companies in Northern Vietnam (e.g. Nestle, Shopee) and 33 companies in the Central of Vietnam (e.g. Heineken, Bosch).

\subsubsection{Study design and construct operationalization}

The research was performed using a cross-sectional design. This method is suitable for identifying and evaluating behaviors and expectations and considered as one of the most commonly utilized designs in social science (Abbott \& McKinney, 2013; de Vaus, 2007). Such a design also permits data collection efficiently and cost-effectively (de Vaus, 2007).

As an attempt to inquire into the potential connection between SC dimensions and companies' performance through knowledge transfer and innovation, this study adopted various measurement items according to existing literature. To obtain a measure for network tie, this study focused on the strength of ties, which is similar to many other pieces of research (i.e. Dato-on et al., 2017; Saha \& Banerjee, 2015). The responses were tested about three items evaluating the closeness of the relationship, the duration of a network, and the frequency of contact (Saha et al., 2015). Beside network ties, another factor taken to represent for SC was trust (i.e. the relational dimension). This construct's measurement comprised four items with two regarding enforceable trust and two regarding generalized trust to evaluate the perception of trust in the samples' companies and the insight of cooperation in networks (Miller et al., 2007; Portes \& Sensenbrenner, 1993). Then, four items were adapted from Miller et al. (2007) concerning organizational commitment and personal socializing opportunity were used to measure the shared vision among members. Six items were used to measure knowledge sharing, including compilation and use of formal or documentary reports (Reychav \& Weisberg, 2010), learning and improvement courses (Liebowitz, 1999) and information technology frameworks (Alavi \& Leidner, 2001). Regarding innovation, there were five items mentioned innovation speed (Chen \& Hambrick, 1995; Liao et al., 2010) and five items reflecting innovation quality (Haner, 2002; Lahiri, 2010). Finally, when it comes to firm performance, the perception of business success, future profitability, and future growth was adopted from past studies to measure firm performance (Sorenson, Goodpaster, Hedberg \& Yu, 2009). A table of measurement items was attached in Appendix A.

\subsubsection{Data collection}

The questionnaire was designed before information collection to capture the relationships between SC and business performance, according to previous empirical studies (Dato-on et al., 2017; Saha et al., 2015; Wang et al., 2012). Then it was piloted to a small, representative sample of participants $(n=15)$ who had been requested to fill in and submit with their comments and feedbacks (Hair, Bush \& Ortinau, 2003). The pilot's goal was to determine if any statements were hard to address because of the sentence structure, transparency, grammar or special terminology (Colton \& Covert, 2007, p. 140). Piloting also helped to enhance construct validity (Shadish, Cook \& Campell, 2002).

The piloting results showed that some items need to be reworded for better comprehension. As an example, the respondents were confused by a few terminologies in the survey, particularly some terms that imply the frequency and duration of networking. In addition, narrow interpretation of network nodes was also a concern as participants frequently find network members consist of nothing more than colleagues and customers and miss a lot of essential network nodes, including suppliers, companies' partners. Thus, those terminologies which are found to be misleading are indicated with brief explanations so that respondents can readily grasp the survey as a whole. Based on the pretest results, the study has further updated the questionnaire to enhance readability and reliability prior to its use in the final survey.

According to Hair, Black, Babin and Anderson (2010), the required sample size must be ten times the total number of indicators. Therefore, a minimal sample size of 310 is required for this study. In fact, 384 questionnaires were delivered to 153 different companies, and 330 were collected, yielding a rate of responding up to $86 \%$. This high response rate reduced the possibility of response bias (Raheel \& Naeem, 2013). Additionally, for none of the survey items was there missing data. 
In terms of sampling method, the study adopted snowball and convenience sampling methods (Trochim \& Donnelly, 2002). Data collection was between October $15^{\text {th }}$ of 2018 and January $5^{\text {th }}$ of 2019 . A number of respondents employed face-to-face interview and online using google form are 193 and 95, respectively.

\section{Results}

\subsection{Respondents' profile}

As observed in Table 1, the proportions of the two genders are approximately equal. In addition, the majority of respondents reported themselves obtaining a bachelor degree (86\%). Regarding business context, there are $61 \%$ of the participants holds the managerial position and $78 \%$ of the respondents coming from Trading and Services companies. Regarding firm age and firm size, the medium scale holds the most significant percentage of $44 \%$ and $55 \%$, respectively.

Table 1

Respondents' profile

\begin{tabular}{|c|c|c|c|}
\hline & Detail & Frequency & Percentage \\
\hline \multirow{2}{*}{ Gender } & Male & 154 & $47 \%$ \\
\hline & Female & 176 & $53 \%$ \\
\hline \multirow{4}{*}{ Education } & High school & 18 & $5 \%$ \\
\hline & Bachelor's or Associate degree & 283 & $86 \%$ \\
\hline & Master's degree & 26 & $8 \%$ \\
\hline & Doctor's degree & 3 & $1 \%$ \\
\hline \multirow{4}{*}{ Position } & Manager & 201 & $61 \%$ \\
\hline & Vice Head/ Head of Department & 76 & $23 \%$ \\
\hline & Director/ Vice Director & 25 & $8 \%$ \\
\hline & Boards of Directors & 28 & $8 \%$ \\
\hline \multirow{2}{*}{ Industry } & Manufacturing & 74 & $22 \%$ \\
\hline & Trading and Services & 256 & $78 \%$ \\
\hline \multirow{4}{*}{ Firm Age } & 3 years or below & 95 & $29 \%$ \\
\hline & From 4 years to 10 years & 146 & $44 \%$ \\
\hline & From 11 years to 20 years & 55 & $17 \%$ \\
\hline & Above 20 years & 34 & $10 \%$ \\
\hline \multirow{4}{*}{ Firm Size } & Below 10 employees & 51 & $15 \%$ \\
\hline & From 10 to 200 employees & 179 & $54 \%$ \\
\hline & Above $200-300$ employees & 23 & $7 \%$ \\
\hline & Above 300 employees & 77 & $23 \%$ \\
\hline
\end{tabular}

\subsection{Data Analysis}

Initially, exploratory factor analysis (EFA) was carried out. Confirmatory factor analysis (CFA) was then used to evaluate the measurements. Finally, structural equation modeling (SEM) was utilized to evaluate the associations between SC, knowledge transfer, innovation, and organizational performance. Moreover, SEM is known to be able to deal with many dependent variables compared to regression technique, which usually has one dependent variable (Ramlall, 2016). In addition, this SEM technique has been applied by an increasing number of scholars from different fields, particularly in measuring the SC dimensions (Youssef, Haak-Saheem \& Youssef, 2017; Fornell \& Larcker, 1981). In running both CFA and SEM, IBM SPSS Amos version 25.0 was used.

\subsubsection{Exploratory factor analysis}

The research initially attempted to validate the instrument by eliminating items having unsatisfied corrected item-to-total correlation values and performing an EFA test to remove items that were not loaded correctly on a factor using ML (maximum likelihood) extraction with Promax rotation. The ML approach is chosen since it delivers a substantial method to solve the question of "number of factors" and usually comes up with better estimates of parameters (O'Rourke \& Hatcher, 2013, p.57). The revised version of the survey is comprised of 31 items, corresponding to six variables, including NET ( 3 items), TRU (4 items), SHA (4 items), KNO (6 items), INO (10 items), FIN (4 items).

\subsubsection{Confirmatory factor analysis}

Two important assumptions to be tested in SEM include multivariate outliers and multivariate normality (Hair et al., 2010; Tabachnick \& Fidell, 2007). The study runs tests for normality and outliers in Amos (Arbuckle, 2013). In detection multivariate outliers, squared Mahalanobis distance $\left(d^{2}\right)$ was calculated. An outer case would have a $d^{2}$ value which is markedly different from other $d^{2}$ values (Byrne, 2016). The study identified a total of 42 outlying cases as candidates for removal. As regards multivariate normality, the $z$-statistic of 7.247, which is smaller than 10 , is suggestive of multivariate normality of the sample (Kline, 2015). Therefore, the qualified sample of 288 observations is ready for further analysis. Furthermore, a CFA 
procedure identified the standardized factor loadings of FIN_1, KNO_5 and KNO_6 that are below 0.70, which are candidates for removal to improve construct convergence. To evaluate construct validity, several measures such as critical ratio (CR), average variance extracted (AVE), maximum shared variance (MSV), average shared variance (ASV) were used (Hair et al., 2010). Results from related measures all passed the cut-off guidelines as shown in Table 2, indicating construct validity and reliability (Hair et al., 2010).

Table 2

Reliability and Convergent Validity of Measured Variables

\begin{tabular}{|c|c|c|c|c|}
\hline Variables & $\mathrm{CR}$ & AVE & MSV & ASV \\
\hline NETWORK TIES & 0.916 & 0.785 & 0.457 & 0.330 \\
\hline TRUST & 0.864 & 0.614 & 0.284 & 0.164 \\
\hline SHARED VISION & 0.889 & 0.667 & 0.309 & 0.178 \\
\hline INNOVATION & 0.956 & 0.685 & 0.578 & 0.335 \\
\hline KNOWLEDGE TRANSFER & 0.851 & 0.588 & 0.578 & 0.278 \\
\hline FINANCIAL PERFORMANCE & 0.796 & 0.565 & 0.346 & 0.216 \\
\hline
\end{tabular}

The study also improved model fit by connecting pairs of e1 and e2, e3 and e8, e5 and e6, and e7 and e10 as shown in Figure 2. All these connections are supported by the literature. More specifically, e1 to e 2 was supported by the fact that being fast in novel ideas can lead to faster new product launch (Ulrich \& Eppinger, 2008). Moreover, Montoya and Calantone (1994) stated that by improving management activities such as product launch practices and new product development managerial activities can lead to a higher success rate of new product launch, proving the connection between e 7 and e10. Besides, the problem-solving ability is proved to link directly with the ability to come up with novel ideas as anything must be novel to be seen as "problem" (Smith, 2012), thus the connection of e5 and e6 was supported. Finally, Lukas and Menon (2004) proved that the pace of new product production has an unfavorable relation to the quality of the product, supporting the connection of $\mathrm{e} 3$ and $\mathrm{e} 8$ in the negative way as the par change is also negative.

\subsubsection{Structural Equation Modeling}

Hypothesis testing was conducted with the SEM model presented in Fig 2. It can be said that have shown that the measurement model matches the data reasonably by the GOF (goodness-of-fit) indices. The chi-square ratio test size and degrees of freedom number [ $\chi^{2} /$ d.f.] equal 2.432 with significant p-value, which is considered good and the RMSEA equals 0.071 considered moderate (Arbuckle, 2007; Hair et al., 2010; Ho, 2006). Together with the traditional Comparative Fit Index of 0.921, the standardized RMR 0.0045 satisfying the requirement of below 0.09 , we concluded that the model fits the data well (Arbuckle, 2007; Hair et al., 2010; Ho, 2006).

Overall, our model was supported. As seen from Table 3, all the p-values are lower than 0.05. Especially, the relationships of $\mathrm{NET} \rightarrow \mathrm{KNO}, \mathrm{KNO} \rightarrow \mathrm{INO}$, INO $\rightarrow$ FIN were of $99 \%$ of the significance level. Moreover, as all the estimate weights appeared to be positive; as a result, all the correlations between variables in the proposed model were also proved to be positive by the data. In conclusion, all five hypotheses were supported. In addition, the relationship between knowledge transfer and innovation were proved to be the strongest as its weight was the highest (i.e. 0.892) at 99\% level of significance.

Table 3

Hypotheses Testing

\begin{tabular}{llllll}
\hline Hypothesis & Relationship & Estimate & S.E. & C.R. & P-value \\
\hline H1 & KNO $\leftarrow$ NET & 0.272 & 0.056 & 4.889 & Decision \\
H2 & KNO $\leftarrow$ TRU & 0.14 & 0.056 & 2.506 & $0.012 *$ \\
H3 & KNO $\leftarrow$ SHA & 0.116 & 0.044 & 2.665 & $0.008 * *$ \\
H4 & INO $\leftarrow$ KNO & 0.892 & 0.073 & 12.214 & $* * *$ \\
H5 & FIN $\leftarrow$ INO & 0.484 & 0.064 & 7.573 & Supported \\
*** significant at $\mathrm{p}<0.001 ; * *$ significant at $\mathrm{p}<0.01 ; *$ significant at $\mathrm{p}<0.05$ & & & &
\end{tabular}

$* * *$ significant at $\mathrm{p}<0.001 ; * *$ significant at $\mathrm{p}<0.01 ; *$ significant at $\mathrm{p}<0.05$

Taken altogether, the results have shown that the research model allows understanding of how SC dimensions affect firm performance. First, this study found that all three dimensions of SC, namely, the strength of network ties, trust, shared visions affect knowledge transfer moderately. Second, the correlation between knowledge transfer and innovation was proved to be very strong. Moreover, we noticed that the correlation between a company innovation and its performance was relatively significant.

\section{Discussion}

Similar to other existing literature, the results show that the significance of these three factors of SC was high during the knowledge transfer process (Davenport \& Prusak, 1998; Saha et al., 2015). It later indicates how it influenced the organizational and financial performance of the firms (Nelson \& Cooprider, 1996; Nguyen \& Ha, 2019; Wang et al., 2012; Saha et al., 2015). As regards the network ties, this study shows that it had a positive relation with knowledge transfer, similar to the 
researches of Hansen (1999) and Uzzi (1997), which stated that strong ties result in better knowledge transfer. Regarding trust, it is found to positively link with knowledge transfer, as had been proved in previous research (e.g. see Tsai \& Ghoshal, 1998). However, Yli-renko, Autio and Sapienza (2001) stated that trust could negatively affect knowledge transfer because of over-embeddedness. Although trust can lead to decrease in the transaction cost in transfer making transfer process runs smoothly, an increase in trust increases also lead to diminishing in the perceived need to monitor and decrease in the level of intense processing of knowledge transferred decrease, which later may not increase knowledge acquisition. Regarding shared vision, it is shown to positively relate to knowledge transfer, similar to Nahapiet and Ghoshal (1998) stating that mutual understanding leads to better sharing intention and better communication for the process of information exchange and knowledge creation ( $\mathrm{Li}, 2005)$.

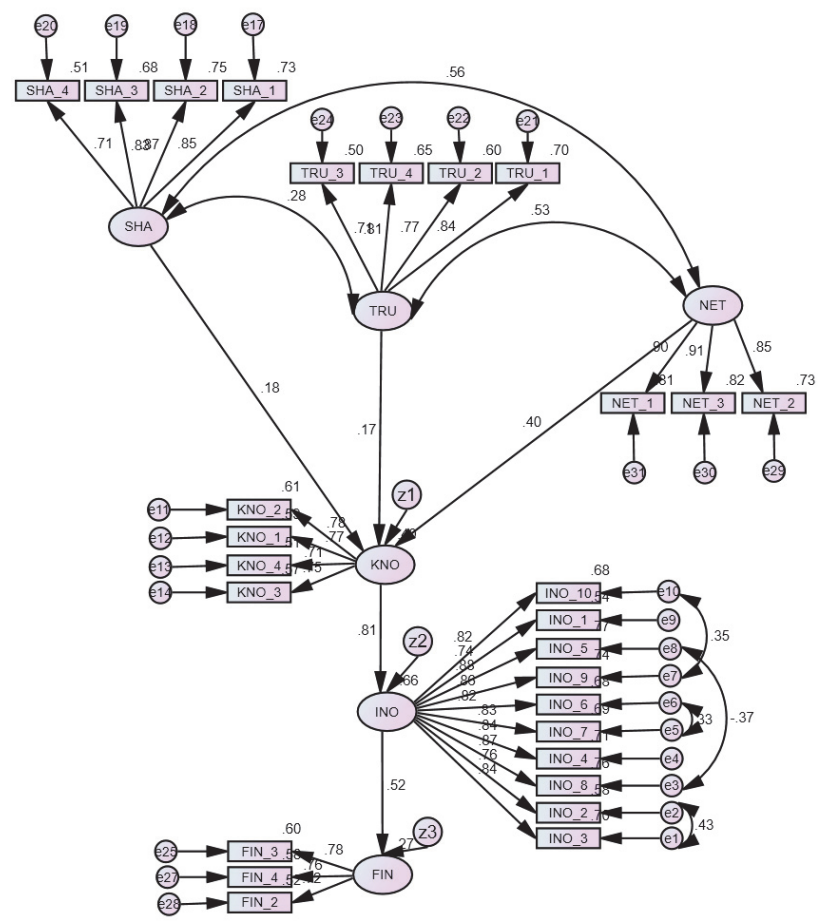

Fig. 2. The final structural equation modeling results

As the connection to the transfer of knowledge and innovation is the strongest effect, there were many previous studies proving this significant correlation such as Katila and Ahuja (2002) on knowledge transfer and new product and innovativeness, Gilbert and Cordey-Hayes (1996) on information transfer as well as technology innovation, Kogut and Zander (1996) on skills transfer and innovation. However, Baum and Ingram (1998) stated that knowledge transfer could have adverse effect on innovation because of the knowledge acquired outside the local market and the inappropriate routines imported from other markets, where competitors were different. Finally, innovation is discovered to have a positive relationship with firm performance. Dato-on et al. (2017) also discovered that innovation and firm performance were highly related. Additionally, it was argued that the knowledge and information sharing might lead to a different level of favorable innovation resulting in different level of firm financial performance (Van Wijk, Jansen, \& Lyles, 2008). However, innovation can be negatively related to firm performance (see Vakhitova \& Pavlenk, 2010). In the case of new product implementation, it may not be related to profitgenerating ability or even reduce productivity due to change in production method, which later hurts performance.

\subsection{Limitations and Further Research}

The paper has a few certain limitations. First, there are only three SC dimensions appearing in the model, whilst other factors can also influence the outcome (i.e. organizational culture, number of ties, network stability). Thus, future research is recommended to be conducted using other factors of SC. Second, the dataset is constrained by the snowball sampling and convenience sampling approach. Therefore, there should be further research examining a specific industry of a defined sector in a specific area, which can collect data population to carry out random sampling method to avoid bias. Third, there may be an intrinsic disadvantage of quantitative analysis to be faced by this study. The items used to explain and measure different dimensions of SC are by no means comprehensive. In other words, the operationalization could not have completely grasped the diversity of facets of each dimension. The limitation can be relatively omitted by incorporating qualitative data in further researches, which could be able to provide deeper network embeddedness understanding. 
Regarding academic contribution, this study is the first research to study and combine the influence of SC on three factors namely intention to knowledge sharing, innovation, and firm performances, especially in Vietnam. In addition, Hitt et al., (2002) also stated that Asian companies are more competitive than Western ones because of their strong SC. Current topics of research include the measurement of SC (Le, 2007; Nguyen, 2013; Tran, 2006), the relationship between SC and firm performance (Tran, 2003), or social, human, and physical capital in general (Le Van et al., 2018). At current, this matter has not been investigated toward firm performance with data analysis, not to mention the mediate role of knowledge transfer and innovation, especially in Vietnam.

\subsection{Practical Implications}

The results of this work will unravel and shed light on the understanding of how all three SC dimensions impact on business performance. First, managers should make sure that the supportive management system within the network members is implemented, as it is crucially important to information sharing intention. Second, it is suggested that a working environment, which motivates trust and openness between employees, should be created. Another implication for managers is to build up not only the close relationship within the network but also to make sure that the exchange of information to be smooth and effective, which can avoid misinformation and misunderstanding so that the effect of transfer can lead to innovation and better business performance.

\section{Conclusion}

This study has shown that all dimensions of SC were significantly associated with business performance with the mediation roles of knowledge exchange and firm innovation. Taken altogether, the results suggest a mechanism by which all three dimensions of SC have influenced on knowledge sharing, which has contributed to innovation and organization performance, with the weights of $0.272,0.14,0.116$ respectively. In other words, the strength of network ties, trust, and shared vision have contributed to business performance by means of the advance of knowledge transfer, innovation speed, and innovation quality. Knowledge transfer was found to favorably impact on innovation with the greatest weight of 0.892 , suggesting a strong correlation. Finally, innovation was also proved to be positively associated with firm performance at 0.484 , suggesting a relatively significant relationship.

\section{References}

Abbott, M. L., \& McKinney, J. (2013). Understanding and applying research design. John Wiley \& Sons.

Adler, P. S., \& Kwon, S. W. (2002). Social capital: Prospects for a new concept. Academy of management review, 27(1), 1740.

Alavi, M., \& Leidner, D. E. (2001). Knowledge management and knowledge management systems: Conceptual foundations and research issues. MIS quarterly, 107-136.

Ali-Hassan, H. (2009). Social Capital Theory. In Handbook of Research on Contemporary Theoretical Models in Information Systems (pp. 420-433). IGI Global.

Andersson, U., Forsgren, M., \& Holm, U. (2002). The strategic impact of external networks: subsidiary performance and competence development in the multinational corporation. Strategic management journal, 23(11), 979-996.

Arbuckle, J. L. (2007). Amos 16.0 [computer software]. Chicago, IL: Smallwaters.

Arbuckle, J. L. (2013). IBM SPSS AMOS 22 Users' Guide: IBM Corp.

Baum, J. A., \& Ingram, P. (1998). Survival-enhancing learning in the Manhattan hotel industry, 1898-1980. Management science, 44(7), 996-1016.

Burns, T. (1973). A structural theory of social exchange. Acta Sociologica, 16(3), 188-208.

Burt, R. S. (1987). Social contagion and innovation: Cohesion versus structural equivalence. American journal of Sociology, 92(6), 1287-1335.

Byrne Barbara, M. (2016). Structural equation modeling with AMOS: basic concepts, applications, and programming. Routledge.

Chen, M. J., \& Hambrick, D. C. (1995). Speed, stealth, and selective attack: How small firms differ from large firms in competitive behavior. Academy of management journal, 38(2), 453-482.

Chow, W. S., \& Chan, L. S. (2008). Social network, social trust and shared goals in organizational knowledge sharing. Information \& management, 45(7), 458-465.

Chuang, L. M. (2005). An empirical study of the construction of measuring model for organizational innovation in Taiwanese high-tech enterprises. Journal of American Academy of Business, 6(1), 299-304.

Clifton, N., Keast, R., Pickernell, D., \& Senior, M. (2010). Network structure, knowledge governance, and firm performance: Evidence from innovation networks and SMEs in the UK. Growth and Change, 41(3), 337-373.

Coleman, J. S. (1988). Social capital in the creation of human capital. American journal of sociology, 94, S95-S120. 
Colton, D., \& Covert, R. W. (2007). Designing and constructing instruments for social research and evaluation. John Wiley \& Sons.

Cook, K. S., Hardin, R., \& Levi, M. (2005). Cooperation without trust?. Russell Sage Foundation.

Dalton, R. J., Hac, P. M., Nghi, P. T., \& Ong, N. N. T. (2002). Social relations and social capital in Vietnam. Comparative Sociology, 1, 369-86.

Dato-on, M. C., Banerjee, S., \& Roy, M. (2018). Innovation support and small-firm performance in India: A social capital perspective. Thunderbird International Business Review, 60(5), 797-807.

Davenport, T. H., \& Prusak, L. (1998). Working knowledge: How organizations manage what they know. Harvard Business Press.

De Vaus, D.A. (2007). Research design in social research. Sage.

Dodgson, M. (1993). Learning, trust, and technological collaboration. Human relations, 46(1), 77-95.

Du Plessis, M. (2007). The role of knowledge management in innovation. Journal of knowledge management, 11(4), $20-29$.

Fornell, C., \& Larcker, D. F. (1981). Evaluating structural equation models with unobservable variables and measurement error. Journal of marketing research, 18(1), 39-50.

Gilbert, M., \& Cordey-Hayes, M. (1996). Understanding the process of knowledge transfer to achieve successful technological innovation. Technovation, 16(6), 301-312.

Granovetter, M. (1983). The strength of weak ties: A network theory revisited. Sociological theory, 201-233.

Gronum, S., Verreynne, M. L., \& Kastelle, T. (2012). The role of networks in small and medium-sized enterprise innovation and firm performance. Journal of Small Business Management, 50(2), 257-282.

Haak-Saheem, W., \& Darwish, T. K. (2014). The role of knowledge management in creating a culture of learning: The case of Dubai Municipality. Management Decision, 52(9), 1611-1629.

Hair Jr Joseph, F., Bush Robert, P., \& Ortinau David, J. (2003). Marketing research: within a changing environment.

Hair, J. F., Anderson, R. E., Babin, B. J., \& Black, W. C. (2010). Multivariate data analysis: A global perspective (Vol. 7).

Hansen, M. T. (1999). The search-transfer problem: The role of weak ties in sharing knowledge across organization subunits. Administrative science quarterly, 44(1), 82-111.

Helliwell, J. F. (1996). Do borders matter for social capital? Economic growth and civic culture in US states and Canadian provinces (No. w5863). National bureau of economic research.

Hitt, M. A., Lee, H. U., \& Yucel, E. (2002). The importance of social capital to the management of multinational enterprises: Relational networks among Asian and Western firms. Asia pacific journal of Management, 19(2-3), 353-372.

Ho, R. (2006). Handbook of univariate and multivariate data analysis and interpretation with SPSS. CRC Press.

Hurley, R. F., \& Hult, G. T. M. (1998). Innovation, market orientation, and organizational learning: an integration and empirical examination. Journal of marketing, 62(3), 42-54.

Jenssen, J. I., \& Greve, A. (2002). Does the degree of redundancy in social networks influence the success of business startups?. International Journal of Entrepreneurial Behavior \& Research.

Jarillo, J. C. (1988). On strategic networks. Strategic management journal, 9(1), 31-41.

Katila, R., \& Ahuja, G. (2002). Something old, something new: A longitudinal study of search behavior and new product introduction. Academy of management journal, 45(6), 1183-1194.

Kline, R. B. (2015). Principles and practice of structural equation modeling. Guilford publications.

Klomp, L., \& Van Leeuwen, G. (2001). Linking innovation and firm performance: a new approach. International Journal of the Economics of Business, 8(3), 343-364.

Kogut, B., \& Zander, U. (1996). What firms do? Coordination, identity, and learning. Organization science, 7(5), $502-518$.

Lahiri, N. (2010). Geographic distribution of R\&D activity: how does it affect innovation quality?. Academy of Management Journal, 53(5), 1194-1209.

Le Van, C., Nguyen, A. N., Nguyen, N. M., \& Simioni, M. (2018). Growth strategy with social capital, human capital and physical capital-Theory and evidence: The case of Vietnam. Journal of Public Economic Theory, 20(5), 768-787.

Le, M.T. (2007). Vốn xã hội và đo lường vốn xã hội (Social capital and measurement of social capital). Tạp chí Khoa học $x \tilde{a} h \hat{o} i, 3,72-77$.

Liao, C., Wang, H. Y., Chuang, S. H., Shih, M. L., \& Liu, C. C. (2010). Enhancing knowledge management for R\&D innovation and firm performance: An integrative view. African Journal of Business Management, 4(14), 3026.

Liebowitz, S. J., \& Margolis, S. E. (1999). Winners, losers \& Microsoft; Competition and antitrust in high technology. Independent Institute.

Lin, N. (2017). Building a network theory of social capital. In Social capital (pp. 3-28). Routledge.

Love, J. H., Roper, S., \& Du, J. (2009). Innovation, ownership and profitability. International Journal of Industrial Organization, 27(3), 424-434.

Lukas, B. A., \& Menon, A. (2004). New product quality: intended and unintended consequences of new product development speed. Journal of Business Research, 57(11), 1258-1264.

Maurer, I., Bartsch, V., \& Ebers, M. (2011). The value of intra-organizational social capital: How it fosters knowledge transfer, innovation performance, and growth. Organization Studies, 32(2), 157-185.

McEvily, B., \& Zaheer, A. (1999). Bridging ties: A source of firm heterogeneity in competitive capabilities. Strategic management journal, 20(12), 1133-1156.

Miller, N. J., Besser, T., \& Malshe, A. (2007). Strategic networking among small businesses in small US communities. International Small Business Journal, 25(6), 631-665. 
Nahapiet, J., \& Ghoshal, S. (1998). Social capital, intellectual capital, and the organizational advantage. Academy of management review, 23(2), 242-266.

Nguyen, D.C. (2013). Vốn xã hội cho sự phát triển ở Việt Nam hiện nay (Social capital in the context of current development in Vietnam). Tạp chí Khoa học xã hội Việt Nam, 7(68), 42-50.

Nguyen, H.T.T. and Ha, T.M. (2019). Impact of Social Capital on Firm Performance: The Case of Manufacturing and Services Firms in Ho Chi Minh City. In: Proceedings of NIDA International Business Conference 2019 - Transforming Business to the Future. [online],193-211. Available at: http://mba.nida.ac.th/files/CONFERENCE\%202019/NIDA\%20International\%20Business\%20Conference\%20Proceeding\%202019.pdf

O'Rourke, N., \& Hatcher, L. (2013). A step-by-step approach to using SAS for factor analysis and structural equation modeling. Sas Institute.

Perry-Smith, J. E. (2006). Social yet creative: The role of social relationships in facilitating individual creativity. Academy of Management journal, 49(1), 85-101.

Portes, A., \& Sensenbrenner, J. (1993). Embeddedness and immigration: Notes on the social determinants of economic action. American journal of sociology, 98(6), 1320-1350.

Putnam, R. D. (1995). Bowling alone: America's declining social capital. Journal of democracy, 6(1), 65-78.

Raheel, H., \& Naeem, N. (2013). Assessing the Objective Structured Clinical Examination: Saudi family medicine undergraduate medical students' perceptions of the tool. J Pak Med Assoc, 63(10), 1281-1284.

Ramlall, I. (2016). Applied structural equation modelling for researchers and practitioners: Using $R$ and Stata for behavioural research. Emerald Group Publishing.

Reychav, I., \& Weisberg, J. (2010). Bridging intention and behavior of knowledge sharing. Journal of Knowledge Management.

Roper, S., Du, J., \& Love, J. H. (2008). Modelling the innovation value chain. Research policy, 37(6-7), 961-977.

Saha, M., \& Banerjee, S. (2015). Social capital and information sharing: impact on firm performance. In Innovation, Finance, and the Economy (pp. 193-211). Springer, Cham.

Salavou, H., \& Lioukas, S. (2003). Radical product innovations in SMEs: the dominance of entrepreneurial orientation. Creativity and innovation management, 12(2), 94-108.

Shadish, W. R., Cook, T. D., \& Campbell, D. T. (2002). Experimental and quasi-experimental designs for generalized causal inference/William R. Shedish, Thomas D. Cook, Donald T. Campbell. Boston: Houghton Mifflin.

Smith, K. G., Collins, C. J., \& Clark, K. D. (2005). Existing knowledge, knowledge creation capability, and the rate of new product introduction in high-technology firms. Academy of management Journal, 48(2), 346-357.

Smith, M. U. (Ed.). (2012). Toward a unified theory of problem solving: Views from the content domains. Routledge.

Song, M., Droge, C., Hanvanich, S., \& Calantone, R. (2005). Marketing and technology resource complementarity: An analysis of their interaction effect in two environmental contexts. Strategic management journal, 26(3), 259-276.

Sorenson, R. L., Goodpaster, K. E., Hedberg, P. R., \& Yu, A. (2009). The family point of view, family social capital, and firm performance: An exploratory test. Family Business Review, 22(3), 239-253.

Subramaniam, M., \& Youndt, M. A. (2005). The influence of intellectual capital on the types of innovative capabilities. Academy of Management journal, 48(3), 450-463.

Tabachnick, B. G., Fidell, L. S., \& Ullman, J. B. (2007). Using multivariate statistics (Vol. 5). Boston, MA: Pearson.

Thibaut, J. W., \& Kelley. HH. (1959). The social psychology of groups. New York.

Thibaut, J. W. (2017). The social psychology of groups. Routledge.

Tran, H.D. 2003. Vốn xã hội và kinh tế (Social capital and economy). Thời Đại, 8: 82- 102.

Tran, H.D. (2006). Vốn xã hội và phát triển kinh tế (Social capital and economic development). Bài viết cho Hội Thảo về Vốn Xã Hội và Phát Triển do tạp chí Tia Sáng và Thời Báo Kinh Tế Sài Gòn tổ chức, Thành phố Hồ Chí Minh-Tháng 6, 32-66.

Trochim, W. M., \& Donnelly, J. P. (2001). Research methods knowledge base (Vol. 2). Cincinnati, OH: Atomic Dog Publishing.

Tsai, W., \& Ghoshal, S. (1998). Social capital and value creation: The role of intrafirm networks. Academy of management Journal, 41(4), 464-476.

Ulrich, K. T. (2003). Product design and development. Tata McGraw-Hill Education.

Uzzi, B. (1997). Social structure and competition in interfirm networks: The paradox of embeddedness. Administrative science quarterly, 35-67.

Vakhitova, G., \& Pavlenko, T. (2010). Innovation and productivity: A firm level study of Ukrainian manufacturing sector. Discussion Papers, 27.

Van Wijk, R., Jansen, J.J. \& Lyles, M.A. (2008). Inter-and intra-organizational knowledge transfer: a meta-analytic review and assessment of its antecedents and consequences. Journal of management studies, 45(4), 830-853.

Wang, Z., \& Wang, N. (2012). Knowledge sharing, innovation and firm performance. Expert systems with applications, $39(10), 8899-8908$.

Wu, W. P. (2008). Dimensions of social capital and firm competitiveness improvement: The mediating role of information sharing. Journal of management studies, 45(1), 122-146.

Yli-Renko, H., Autio, E., \&Sapienza, H. J. (2001). Social capital, knowledge acquisition, and knowledge exploitation in young technology-based firms. Strategic management journal, 22(6-7), 587-613. 
Youssef, M., Haak-Saheem, W., \& Youssef, E. M. (2017). A structural equation model for knowledge sharing behavior in an emerging economy. Journal of Knowledge Management, 21(4), 925-945.

Van Wijk, R., Jansen, J. J., \& Lyles, M. A. (2008). Inter-and intra-organizational knowledge transfer: a meta-analytic review and assessment of its antecedents and consequences. Journal of management studies, 45(4), 830-853.

\section{Appendix A}

Measurement

1. Structural Dimension: Network Ties (Grantovetter, 1973; Gronum et al., 2012; Perry-Smith, 2006)

NET 1 How is the closeness between you and your network members?

NET 2 How long have your networks exist?

$(1=$ Less than 1 year, $2=$ From 1 to 3 years; $3=$ From 4 to 6 years, $4=$ From 7 to 9 years, $5=10$ years or more $)$

NET_3 Normally (on average), how often do you communicate with members of your network regarding business issues? $(1=$ once a year or less, $2=$ six times a year, $3=$ once a month, $4=$ once a week, $5=$ daily $)$

2. Relational Dimension: Trust (Miller et al., 2007; Portes and Sensenbrenner, 1993)

TRU_1 I completely/ wholeheartedly trust the members within my networks.

TRU_2 I believe that members within my networks will always keep their words.

TRU_3 I believe that members within my networks highly trust each other.

TRU_4 Members in my network usually collaborate with each other.

3. Cognitive Dimension: Shared vision (Miller et al., 2007; Saha and Banerjee, 2015)

SHA_1 I believe that members within my networks share the same sets of ambitions and visions.

SHA 2 I believe that networks' members always care for the fate of each other's businesses.

SHA_3 Network members devote their resources (money, time, technology, excess inventory, etc.) to help each other.

SHA 4 I believe that networks can provide socializing opportunities for individuals.

4. Knowledge Transfer (Reychav and Weisberg, 2010; Liebowitz, 1999; Alavi and Leidner, 2001)

KNO 1 Members of my networks usually share official reports and documents to each other.

KNO_2 Members of my networks usually share reports and documents that they prepare by themselves to each other.

KNO_3 People in my networks frequently collect official reports and documents from each other for their work.

KNO_4 Members of my networks are frequently encouraged by means of knowledge-sharing.

KNO_5 Members of my networks are usually offered various training and developing programs.

KNO_6 Members of my networks are enabled by IT systems made for knowledge-sharing.

5. Innovation (Chen and Hambrick, 1995; Lahiri, 2010; Liao et al., 2010)

INO_1 Compared to key competitors, my company is quicker in coming up with novel ideas.

INO_2 My company is quicker in terms of new product launching compared to key competitors.

INO_3 My company is quicker in terms of new product development compared to key competitors.

INO_4 My company is quicker in terms of new processes compared to key competitors.

INO_5 My company is quicker in terms of problem solving compared to key competitors.

INO 6 My company is better/ do a better job in coming up with novel ideas compared to key competitors.

INO_7 My company is better/ do a better job in new product launching compared to key competitors.

INO 8 My company is better/ do a better job in new product development compared to key competitors.

INO_9 My company is better/ do a better job in new processes compared to key competitors.

INO_10 My company is better/ do a better job in problem solving compared to key competitors.

6. Financial Firm Performance (Sorenson et al., 2009)

FIN_1 Based on your knowledge, what has been the trend of your company's growth or decline in the past 2-3 years? $1=$ Decrease more than $10 \%, 2=$ Decrease $5 \%$ to $10 \%, 3=$ Stay the same, $4=$ Increase $5 \%$ to $10 \%, 5=$ Increase more than $10 \%$

FIN 2 Has your company/ business gained profit in the last 2-3 years?

$1=$ Not any in 2-3 years, 2 = One year of the past 2-3 years, $3=$ Almost all of the past 2-3 years, and $4=$ Every year

FIN_3 In case your company had profit in the past 2-3 years, how would you describe the trend of profit?

( $1=$ Slightly decrease; $2=$ Stable; $3=$ Slightly increase; $4=$ Significant increase $)$

FIN_4 How would you generalize your company's market share in the past 2-3 years? $(1=$ Slightly decrease; $2=$ Stable; $3=$ Slightly increase; $4=$ Significant increase $)$ 
(C) 2020 by the authors; licensee Growing Science, Canada. This is an open access article distributed under the terms and conditions of the Creative Commons Attribution (CC-BY) license (http://creativecommons.org/licenses/by/4.0/). 